\title{
TOTALITARISMO Y LITERATURA: LA NOVELA CUBANA CONTEMPORĀNEA
}

\author{
Augusto A. Portuondo
}

El objeto de este artículo es determinar la relación entre revolución y literatura en Cuba; en particular, las diversas maneras en que los cambios político-sociales ocurridos en Cuba desde 1959 han afectado la novela cubana contemporánea. Por "novela cubana," entiendo la escrita por cubanos, vivan en Cuba o fuera de ella. Por "contemporánea," entiendo las novelas publicadas desde 1959.

El número de novelas cubanas publicadas en los últimos años no tiene precedentes. Más de un centenar han sido publicadas en Cuba o en otros paises desde el triunfo de la Revolución. Esta cifra incluye sólo esfuerzos literarios serios y, debido a las dificultades en obtener información de Cuba, es seguramente incompleta. La calidad de estas obras es, por necesidad, muy irregular, pero un número apreciable de ellas son obras de arte que pueden compararse favorablemente con los mejores productos del "boom" de la novela latinoamericana y también con novelas de otros países.

Este fenómeno es, sin duda, parte del auge general de la novela latinoamericana, pero ciertas causas nacionales no pueden ser ignoradas. La heroica lucha contra la dictadura de Batista y los cambios en las estructuras económicas, políticas y sociales del país, proveyeron un material novelable de primera mano. Estos materiales han sido aprovechados por diversos autores de vario talento literario que se han referido, por la mayor parte, a la lucha contra Batista. Significativamente, los cambios revolucionarios en la estructura del país han recibido mucho menos atención. Otro factor ha sido la política oficial de la Revolución, protegiendo y auspiciando las artes en general y la literatura en particular. Entre las medidas más efectivas han estado las actividades de la Casa de las Américas, especialmente los prestigiosos premios decididos por jurados qué han incluido escritores de estatura continental, tales como Mario Vargas Llosa y Julio Cortázar. Según Alberto Baeza Flores, el poeta y novelista chileno que vivió muchos años en Cuba y vive ahora en el exilio: "Nunca, en la historia de Cuba, el escritor y el artista habían sido tan halagados y se les había ofrecido tantas ventajas materiales como bajo el régimen de Castro, que los necesitaba. Nunca se editó tanto. Nunca se les dio tanta resonancia y publicidad, tanta categoría e importancia."1

La política oficial del régimen fue expresada por Fidel Castro en junio de 1961, en sus ya famosas Palabras a los intelectuales:

dentro de la Revolución, todo; contra la Revolución, nada... Nosotros no le prohibimos a nadie que escriba sobre el tema que prefiera. Al contrario. Y que cada cual se exprese en la forma que estime pertinente y que exprese libremente la idea que desea 
expresar. Nosotros apreciaremos siempre su creación a través del prisma del cristal revolucionario. Ese también es un derecho del Gobierno Revolucionario, tan respetable como el derecho de cada cual a expresar lo que quiera expresar. ${ }^{2}$

Estas palabras han sido estimadas como prueba de la libertad intelectual en Cuba. En mi opinión ellas son una indicación del carácter crecientemente totalitario del régimen y anticipan hechos que habrían de afectar profundamente esa misma libertad intelectual supuestamente garantizada por esta declaración. En su discurso Fidel Castro definía lo que era admisible en un intelectual en Cuba en 1961 y lo que no lo era. La literatura antirrevolucionaria no era admisible, y esto no es sorprendente, pero abstenerse de atacar la Revolución no era suficiente para ser tolerado: la palabra escogida para la parte afirmativa de la declaración fue "dentro" de la Revolución. La creación literaria "fuera" de la Revolución, aún cuando se abstuviera de atacarla, no era tolerable. El intelectual, para sobrevivir, había de apoyar al régimen. Lo que Castro está realmente definiendo aquí no es tanto la libertad, o falta de ella, de los intelectuales en Cuba, sino el carácter totalitario del sistema político. No hay que decir que la definición de lo que es revolucionario y lo que no lo es viene dada por la Revolución, no el intelectual, y que la Revolución y el gobierno son uno.

Ya en 1961 algunos intelectuales empezaron a tener dificultades con el régimen. Estos, desde luego, eran intelectuales revolucionarios, ya que otros no eran tolerados. Se consideró que Lunes de Revolución, el suplemento cultural del periódico oficial del gobierno, Revolución, no era bastante ortodoxo. Guillermo Cabrera Infante, director del suplemento, y otros periodistas responsables de su publicación, fueron amonestados por no adherirse estrictamente a la política oficial del partido. En definitiva Lunes cesó de publicarse y sus principales directores fueron enviados al exterior. ${ }^{3}$ Pero el punto crucial en las relaciones del régimen y los intelectuales en Cuba fue el caso Padilla.

En octubre de 1968 el libro de Heberto Padilla, Fuera del juego, recibió el premio de poesía de la Unión Nacional de Escritores y Artistas Cubanos. Los miembros del jurado - del que formaba parte Lezama Lima -, pensaron que tenían que justificar su decisión, desde un punto de vista político, ya que algunos de los poemas no eran enteramente laudatorios de la Revolución. ${ }^{4}$ Según el jurado:

La fuerza, y lo que le da sentido revolucionario a este libro es, precisamente, el hecho de no ser apologético, sino crítico, polémico, y estar esencialmente vinculado a la idea de la Revolución como la única solución posible para los problemas que obsesionan a su autor, que son los de la época que nos ha tocado vivir. ${ }^{5}$

Esto, sin embargo, no fue suficiente. El 28 de octubre de 1968 el comité director de Unión se reunió con los miembros del jurado y acusó a Padilla y a Antón Arrufat, que había recibido el premio de teatro por su obra Siete contra Tebas, de difamar y traicionar la Revolución. La declaración de Unión, publicada con el libro, añadía que "el respeto de la revolución cubana por la libertad de expresión. . . no puede ser puesto en duda." 20 de marzo de 1971 Padilla fue arrestado. El 27 de abril compareció ante una reunión de Unión. Después de una breve introducción por José Antonio Portuondo, Padilla declaró que había sido arrestado por contrarrevolucionario, que había "insultado" y "calumniado" la Revolución, y que estas acciones eran y serían siempre su "vergüenza." 
Añadió que sus errores eran "realmente imperdonables," "realmente incalificables," y que ahora se sentía "verdaderamente feliz" porque podría reiniciar su vida. También se llamó a sí mismo "cobarde" y "traidor," y rechazó su propio libro."

La confesión de Padilla fue también una advertencia expresa para otros escritores que se encaminaban en la misma dirección en que él lo había hecho - la mayor parte presentes en esta reunión -, tales como su propia esposa, Pablo Armando Fernández, César López, José Yanes, Manuel Díaz Martínez, David Buzzi y Lezama Lima. Este, en particular, había sido desagradecido con la Revolución que había publicado sus libros a pesar de no ser marxista-leninistas.

El arresto de Padilla tuvo inmediatamente repercusiones internacionales. Cierto número de intelectuales que apoyaban la Revolución firmaron una carta exhortando a Fidel Castro a libertar a Padilla y permitir libertad de expresión. Entre ellos se encontraban Simone de Beauvoir, Italo Calvino, Julio Cortázar, Carlos Fuentes, Gabriel García Márquez, Juan y Luis Goytisolo, Alberto Moravia, Octavio Paz, Mario Vargas Llosa y Jean Paul Sartre. Después de la auto-acusación de Padilla otra carta, consignando su "vergüenza" y su "cólera," fue dirigida a Castro por los escritores anteriormente mencionados y otros más. Algunos de los nuevos nombres fueron los de José Revueltas, Juan Rulfo y Susan Sontag. Los nombres de Cortázar y García Márquez no aparecieron esta vez. El 30 de abril, en un discurso en el Primer Congreso Nacional de Educación y Cultura, Castro declaró que en el futuro, para recibir un premio literario, había que ser "un verdadero revolucionario, un verdadero escritor, un verdadero poeta, un verdadero revolucionario. Eso está claro. Más claro que el agua." Sus críticos eran "burgueses," "calumniadores," "agentes de la CIA," "espías del imperialismo" y "ratas."8

La producción de novelas en Cuba, en los años más recientes, ha declinado, y sus rasgos más característicos, exigidos por el régimen, son falta de experimentación, lenguaje directo y simple, y propaganda. Quizás una de las más representativas de estas novelas es La última mujer y el próximo combate de Manuel Cofiño López, elogiada por José Antonio Portuondo porque "la imaginación creadora está al servicio de ... un objetivo político."

El concepto de "Novela de la Revolución Cubana" necesita ser clarificado. El término ha sido usado por numerosos autores, tales como Luis Agüero, ${ }^{10}$ Rose B. Drummond $^{11}$ y Seymour Menton. ${ }^{12}$ No hay dudas de que las novelas cuyo tema es la lucha contra la dictadura de Batista, o los cambios introducidos en la sociedad cubana por la implantación de un sistema socialista, son novelas de la Revolución. Pero la aplicación indiscriminada de este concepto no es admisible. En algunos casos el término ha sido aplicado a novelas cuyo contenido no tenía nada que ver con la Revolución Cubana. ${ }^{13}$ Las mejores novelas contemporáneas cubanas, las más conocidas, las más originales e innovadoras, no son novelas de la Revolución. Paradiso de Lezama Lima, Tres tristes tigres de Cabrera Infante, De donde son los cantantes y Cobra de Severo Sarduy, El siglo de las luces, Concierto barroco, El derecho de asilo y El recurso del método de Alejo Carpentier, y Celestino antes del alba y El mundo alucinante de Reynaldo Arenas, para mencionar tan sólo algunos de los ejemplos más notables, no son novelas de la Revolución.

Otras consideraciones de orden extra-literario requiren la cuidadosa aplicación de este concepto que, en último análisis, es tanto literario como político. Un número 
significativo de novelistas cubanos que se identificaron con la Revolución, o que al menos permanecieron en Cuba después de 1959, han abandonado el país. Entre ellos se encuentran Cabrera Infante, Juan Arcocha, Hilda Perera, Nivaria Tejera y Severo Sarduy. David Buzzi pasó algún tiempo en la cárcel, José Lorenzo Fuentes fue arrestado por supuestas actividades contrarrevolucionarias y Luis Agüero fue condenado a trabajos forzados por querer salir de Cuba. Carpentier continúa apoyando al régimen, pero vive en París. Siglo XXI, la editorial mexicana que ha publicado sus últimas novelas, se refiere a él como "el novelista de la Revolución Cubana," pero, según George O. Schanzer, en ocasión de la salida de Carpentier de Cuba en 1968, después de ser relevado de su cargo de Director de la Editorial Nacional de Cuba, Radio Habana se refirió a él como "un escritor rodeado de controversias." 4 Y sus novelas, a pesar de la línea de propaganda de Siglo XXI, no están relacionadas con la Revolución. El siglo de las luces se refiere al impacto de la Revolución Francesa en el Caribe; Concierto barroco relata los viajes de un rico indiano en Nueva España y Europa, aunque corta a través de límites temporales; $E l$ derecho de asilo cuenta la transformación de un hombre que, de asilado en una embajada de cierto país latinoamericano, acaba por suplantar al embajador, y El recurso del método es la historia del dictador de una república latinoamericana, con características de varios países, durante las primeras décadas del siglo XX. Carpentier ha estado anunciando durante varios años su "novela de la Revolución," pero hasta ahora solamente ha podido publicar tres capítulos.

En conclusión, el advenimiento de la Revolución fue muy favorable a la producción literaria en Cuba, con incentivos para el escritor y relativa libertad artística. Esta situación cambió gradualmente con el endurecimiento de la actitud del gobierno hacia las artes, hasta que en 1971, con el caso Padilla, las relaciones entre la Revolución y la literatura hicieron crisis. Como resultado de esto, el escritor fue limitado en su actividad creadora y la política oficial exigió una literatura popular, simple y propagandística. El concepto de "Novela de la Revolución" ha sido aplicado en forma muy poco rigurosa. Es sólo legítimo incluir en esta categoría las novelas que tratan de la lucha contra Batista o los cambios socio-económicos ocurridos en el país. No es aplicable a un crecido número de novelas que nada tienen que ver con la Revolución. La mayoría de las novelas cubanas contemporáneas más originales e innovadoras no pueden ser llamadas novelas de la Revolución.

\author{
Dept. of Modern Foreign Languages \\ Clinch Valley College \\ Wise, Virginia - USA
}




\section{NOTAS}

1 Alberto Baeza Flores, "La cultura cubana en la encrucijada de su decenio conflictivo 1959-1969," en Diez años de revolución cubana (Río Piedras, P.R.: Editorial San Juan, 1970), p.76.

${ }^{2}$ Fidel Castro, Palabras a los intelectuales (La Habana: Consejo Nacional de Cultura, 1961), pp.11, 20-21.

${ }^{3}$ Para una relación detallada véase K. S. Karol, Los guerrilleros en el poder (Barcelona: Seix Barral, S.A., 1972), pp.262-268.

${ }^{4}$ Uno de los poemas que parece haber sido más objetable es el titulado "En tiempos difíciles," que reproduzco a continuación:

A aquel hombre le pidieron su tiempo para que lo juntara al tiempo de la Historia.

Le pidieron las manos, porque para una época difícil nada hay mejor que un par de buenas manos.

Le pidieron los ojos que alguna vez tuvieron lágrimas para que contemplara el lado claro (especialmente el lado claro de la vida) porque para el horror basta un ojo de asombro.

Le pidieron sus labios resecos y cuarteados para afirmar, para erigir, con cada afirmación, un sueño (el-alto-sueño);

le pidieron las piernas, duras y nudosas, (sus viejas piernas andariegas) porque en tiempos difíciles ¿ algo hay mejor que un par de piernas para la construcción o la trinchera?

Le pidieron el bosque que lo nutrió de niño con su árbol obediente.

Le pidieron el pecho, el corazón, los hombros.

Le dijeron

que eso era estrictamente necesario

Le explicaron después

que toda esta donación resultaría inútil

sin entregar la lengua, porque en tiempos difíciles nada es tan útil para atajar el odio o la mentira.

$\mathrm{Y}$ finalmente le rogaron que, por favor, echase a andar, porque en tiempos difíciles esta es, sin duda, la prueba decisiva. 
5 Ibíd., p.88.

${ }^{6}$ Ibíd. p.90.

${ }^{7}$ Lourdes Casal, El caso Padilla (Miami: Ediciones Universal, 1971), pp. 78-104.

${ }^{8}$ Ibíd., pp. 115-122.

9 José Antonio Portuondo, reseña de La última mujer y el próximo combate, de Manuel Cofiño López, Casa de las Américas, 12, no. 71 (1972), p.105.

${ }^{10}$ Luis Agüero, "La novela de la Revolución," Casa de las Américas, 4, nos. 22-23 (1964), pp.60-67.

11 Rose B. Drummond, "The Cuban Revolutionary Novel, 1959-1969," tesis M. A. University of California en Los Angeles 1971.

12 Seymour Menton, "The Cuban Novel of the Revolution: A Decade of Growing National Consciousness" en The Cry of Home: Cultural Nationalism and the Modern Writer (Knoxville: University of Tennessee Press, 1972), pp.320-333.

pp. $231-241$.

"La novela de la Revolución cubana," Cuadernos Americanos, 23, no. 1 (1964), Prose Fiction of the Cuban Revolution (Austin: University of Texas Press, 1975).

13 Este es el caso de la obra de Seymour Menton Prose Fiction of the Cuban Revolution.

${ }^{14}$ George O. Schanzer, "Carpentier fallen from grace," Hispania, 51 (1968), p.188. 